\title{
PENGARUH METODE EKSTRAKSI DAN UKURAN BENIH TERHADAP MUTU FISIK-FISIOLOGIS BENIH Acacia crassicarpa
}

\author{
(The Influence of Seed Extraction Method and Seed Size for Maintaining for \\ Physical and Physiological of Acacia crassicarpa) \\ Naning Yuniarti*, Megawati ${ }^{1}$, dan Budi Leksono ${ }^{2)}$ \\ ${ }^{1)}$ Balai Penelitian Teknologi Perbenihan Tanaman Hutan \\ Jl. Pakuan Ciheuleut PO.Box 105 Bogor Telp./Fax. (0251) 8327768 \\ ${ }^{2)}$ Balai Besar Penelitian Bioteknologi dan Pemuliaan Tanaman Hutan \\ Jl. Palagan Tentara Pelajar Km.15, Purwobinangun, Pakem, Sleman, Yogyakarta 55582 \\ Telp. (0274) 895954, Fax. (0274) 896080 \\ *email : naningbtp@yahoo.co.id
}

Naskah masuk : 21 Januari 2013; Naskah diterima : Juli 2013

\begin{abstract}
Seed extraction methods will influence the physical and physiological quality of seed produced. The physical and physiological seed quality is as well influenced by the size of seed. The purpose of this research was to determine of influence of extraction method and the best size of seed on the physical and physiology quality of improved and unimprove seed of Acacia crassicarpa. Seed extraction was conducted by means of drying under the sun heat and drying in the seed dryer for the duration of one until five days. Experimental design used was completely randomized. Seed dimension classification (length, width, and thickness) was determined with sieve/mesh, and seed weight classification with Seed Gravity Table. The results showed that to maintain the quality of the physical-physiological improved and unimprove A. crassicarpa seed require an approriate extraction method and seed size, namely: (1) seeds which were dried with seed dryer for 4 hours or dried under the sun heat for 3 days, and (2) the largest and the heaviest seeds have better viability than seed size of medium, small and lighty. This research also showed that improved seeds can produce better physical and physiological seed qualities than unimproved seeds.
\end{abstract}

Keywords: A.crassicarpa, extraction, improved seed, seed size, physiology quality

\begin{abstract}
ABSTRAK
Metoda ekstraksi benih akan mempengaruhi mutu fisik dan fisiologis benih yang dihasilkan. Selain itu, mutu fisik dan fisiologis benih juga dipengaruhi oleh faktor ukuran benih. Penelitian ini bertujuan untuk mengetahui pengaruh metoda ekstraksi dan ukuran benih terhadap mutu fisik-fisiologis benih hasil pemuliaan dan yang belum dimuliakan untuk jenis $A$. crassicarpa. Ekstraksi benih dilakukan dengan cara pengeringan, yaitu dengan penjemuran di bawah sinar matahari dan menggunakan alat pengeringan (seed drier). Pengeringan dengan cara penjemuran di bawah sinar matahari dilakukan selama $1 \mathrm{~s} / \mathrm{d} 5$ hari dan dengan cara seed drier dilakukan selama $1 \mathrm{~s} / \mathrm{d} 5 \mathrm{jam}$. Rancangan percobaan yang digunakan adalah Acak Lengkap. Sedangkan untuk mendapatkan klasifikasi ukuran benih $A$. crassicarpa berdasarkan dimensi benih (panjang, lebar, dan tebal) digunakan ayakan/mesh, dan klasifikasi berdasarkan berat digunakan alat Seed gravity Table. Hasil penelitian menunjukkan bahwa metoda ekstraksi dan ukuran benih yang terbaik untuk benih hasil pemuliaan dan yang belum dimuliakan, yaitu : (1) Ekstraksi benih dengan cara pengeringan seed drier selama 4 jam atau dengan cara penjemuran sinar matahari selama 3 hari dan (2) Benih yang berukuran besar dan paling berat memiliki viabilitas lebih baik dibandingkan dengan benih berukuran sedang, kecil dan ringan. Hasil penelitian juga menunjukkan bahwa benih hasil pemuliaan dapat menghasilkan mutu fisik fisiologis yang lebih baik dibandingkan dengan yang belum dimuliakan.
\end{abstract}

Kata kunci : $A$. crassicarpa, ekstraksi, ukuran benih, mutu fisik-fisiologis, hasil pemuliaan

\section{PENDAHULUAN}

Dalam pengembangan hutan tanaman, program pemuliaan merupakan salah satu kunci keberhasilan yang dapat menghasilkan benih ung- gul sehingga akan meningkatkan produktivitas tanaman hutan lebih tinggi dibandingkan dengan menggunakan benih biasa. Benih hasil pemuliaan merupakan investasi yang penting dan mahal sehingga perlu ditangani benar agar mutu benihnya, 
baik mutu fisik, fisiologis, dan genetik tetap terjamin baik (Leksono,2009). Sampai saat ini jenis tanaman hutan hasil pemuliaan yang telah diproduksi dari jenis Acacia sp. unggulan tanaman penghasil pulp salah satu diantaranya adalah $A$. crassicarpa.

Mutu fisik dan fisiologis merupakan cerminan dari rangkaian proses penanganan benih dari mulai dari proses produksi sampai pengecambahan benih (Barner and Ditlevsen, 1988). Sedangkan mutu genetik menunjukkan tingkat kemurnian varietas yang dihasilkan dari kinerja pemuliaan pohon (tree improvement) (Barner and Ditlevsen, 1988). Mutu genetik juga didefinisikan sebagai tingkat keterwakilan keragaman genetik suatu sumber benih (IFSP, 2000). Untuk mempertahankan mutu fisik-fisiologis benih hasil pemuliaan agar terjamin baik, diperlukan penanganan benih secara tepat (Barner and Ditlevsen, 1988). Salah satu tahapan awal dalam kegiatan penanganan benih yaitu kegiatan ekstraksi benih yaitu proses pengeluaran benih dari buah, polong, atau bahan pembungkus benih lainnya (Schmidt, 2000). Menurut Hamzah (1984) ekstraksi benih merupakan proses memisahkan benih dari anggota reproduksi yang lain. Metoda ekstraksi benih dari buah ditentukan oleh karakteristik dari masing-masing buah. Proses ekstraksi dapat berupa kegiatan-kegiatan pelunakan daging buah dan pelepasan daging buah, pengeringan, pemisahan, penggoncangan, perontokan, pembuangan sayap, dan pembersihan. Tujuan dari ekstraksi benih adalah menghasilkan benih yang mempunyai viabilitas maksimum (Willan, 1985).

Metode ekstraksi benih akan sangat mempengaruhi mutu benih yang dihasilkan (Schmidt, 2000). Ekstraksi benih A. crassicarpa dapat dikategorikan sebagai cara kering. Pada cara kering, benih dikeluarkan dengan mengeringkan buah dengan menggunakan alat pengering (seed drier) atau dengan cara menjemur buah di bawah sinar matahari (Schmidt, 2000). Ekstraksi benih $A$. crassicarpa dilakukan dengan cara menjemur polong di bawah sinar matahari selama 3-4 hari sampai polong merekah (terbuka), sehingga benih dapat dengan mudah dikeluarkan. Funikel (tangkai biji) dihilangkan dengan cara menjemur benih selama 1-2 hari, kemudian funikelnya dilepaskan dengan cara menggosok benih dengan telapak tangan selanjutnya ditampi atau diayak untuk memisahkan benih dari funikel (Sapulete, E. 1996). Selain metoda ekstraksi benih, mutu benih juga dipengaruhi oleh faktor ukuran benih. Menurut Schmidt (2000), ukuran benih terkadang berkorelasi dengan viabilitas dan vigor be- nih, dimana benih yang berat cenderung mempunyai vigor yang lebih baik. Sorensen dan Campbell (1993), menyatakan ukuran benih dalam bentuk berat dan ukuran dimensi yang lebih besar lebih banyak dipilih karena umumnya berhubungan dengan kecepatan berkecambah dan perkembangan semai yang lebih baik, tetapi ini akan membuang benih berukuran lebih kecil yang mungkin mempunyai genetik lebih baik (Schmidt, 2000).

Tulisan ini menyajikan pengaruh metoda ekstraksi dan ukuran benih terhadap mutu fisik-fisiologis benih hasil pemuliaan dan yang belum dimuliakan untuk jenis $A$. crassicarpa .

\section{METODE PENELITIAN}

\section{A. Waktu dan Tempat}

Penelitian dilakukan selama tiga bulan, yaitu bulan Agustus sampai dengan Oktober 2011. Penelitian dilaksanakan di laboratorium dan rumah kaca Balai Penelitian Teknologi Perbenihan Tanaman Hutan Bogor.

\section{B. Bahan dan Alat}

Benih A. crassicarpa diperoleh dari sumber benih hasil pemuliaan dan yang belum dimuliakan. Sumber benih hasil pemuliaan diwakili oleh kebun benih semai (KBS), yang terdapat di lokasi PT. Musi Hutan Persada, Sumatera Selatan dan PT. Arara Abadi, Riau. Sedangkan sumber benih yang belum dimuliakan diwakili oleh areal produksi benih (APB), yang terdapat di lokasi PT. Inhutani II Kalimantan Selatan, PT. Wira Karya Sakti Jambi, PT. Arara Abadi Riau, dan Hutan Penelitian Parung Panjang, Jawa Barat.

Bahan dan alat yang digunakan dalam penelitian ini adalah tampah/nyiru, terpal plastik, seed drier, kantong plastik, karung, kayu, plastik $\mathrm{klip}$, label, ayakan/mesh ukuran 2,4 x $2 \mathrm{~mm}$ dan $2 \times 1,9 \mathrm{~mm}$, seed gravity table, oven, desikator, timbangan analitik, cawan porselen, silica gel, kertas merang, cawan petri, germinator, sprayer, dan alat tulis.

\section{Metode}

\section{Pengunduhan buah}

Pengunduhan buah $A$. crassicarpa dilakukan sebanyak 20 pohon dari masing-masing lokasi. Pengunduhan buah dilakukan dengan cara memanjat pohon. Buah yang diunduh adalah benih yang sudah masak fisiologis, yang dicirikan de- 
ngan warna polong coklat. Kemudian buah hasil pengunduhan dimasukkan ke dalam karung dan dibawa ke Bogor untuk dilakukan proses pengujian selanjutnya, yaitu ekstraksi benih.

\section{Metode ekstraksi benih}

Ekstraksi benih A. crassicarpa dilakukan dengan cara pengeringan, yaitu dengan cara penjemuran di bawah sinar matahari dan dengan menggunakan alat pengeringan (seed drier). Pengeringan dengan cara penjemuran di bawah sinar matahari dilakukan selama 1, 2, 3, 4, dan 5 hari pada bulan April 2011 di lapangan penjemuran. Sedangkan pengeringan dengan cara seed drier Merk Mectron 10 m dilakukan selama 1, 2, 3,4 , dan 5 jam pada suhu $45^{\circ} \mathrm{C}$.

Rancangan percobaan yang digunakan dalam penelitian ini adalah Acak Lengkap sebagai berikut:

- Lama pengeringan seed drier:

A1: 1 jam

A2: 2 jam

A3: 3 jam

A4: 4 jam

A5: $5 \mathrm{jam}$

- Lama penjemuran sinar matahari:

A1: 1 hari

A2: 2 hari

A3: 3 hari

A4: 4 hari

A5: 5 hari

Model linier yang digunakan :

$\mathrm{Y}_{\mathrm{ij}}=\mu+\mathrm{A}_{\mathrm{i}}+\varepsilon_{\mathrm{ij}}$

(Gomez, K.A dan Arturo, A.G., 1995)

Dimana:

Yij $=$ Nilai hasil pengamatan akibat pengaruh perlakuan (seed drier/sinar matahari) ke$\mathrm{i}$, dan ulangan ke-j

$\mu=$ Nilai rata-rata umum

$\mathrm{Ai}=$ Pengaruh perlakuan (seed drier/sinar matahari) ke-i

$\varepsilon \mathrm{ij}=$ Kesalahan percobaan akibat pengaruh perlakuan (seed drier/sinar matahari) ke-i dan ulangan ke- $\mathrm{j}$

Ulangan sebanyak 4 kali@ 1 kg buah/polong untuk rendemen benih,4 ulangan@100 butirbenih untuk uji perkecambahan dan 4 ulangan @ 5 gram benih untuk uji kadar air. Sedangkan parameter yang diamati dalam penelitian ini adalah rendemen benih dari $1 \mathrm{~kg}$ buah/polong, daya berkecambah, dan kadar air benih.
3. Penentuan klasifikasi ukuran benih

Klasifikasi ukuran benih $A$. crassicarpa ditentukan berdasarkan ukuran dimensi benih (panjang, lebar, dan tebal) dan berat benih. Untuk mendapatkan 3 klasifikasi ukuran benih berdasarkan dimensi, digunakan ukuran ayakan/mesh ukuran besar (tertahan di ayakan berukuran 2,4 $\mathrm{mm}$ x 2 $\mathrm{mm}$ ), ukuran sedang (lolos dari ayakan berukuran 2,4 $\mathrm{mm} \times 2 \mathrm{~mm}$ dan tertahan di ayakan berukuran $2 \mathrm{~mm}$ x 1,9 mm), dan ukuran kecil (lolos dari ayakan berukuran $2 \mathrm{~mm}$ x 1,9 mm). Untuk mendapatkan klasifikasi ukuran benih berdasarkan berat pada benih $A$. crassicarpa, digunakan alat seed gravity table dan diperoleh 4 klasifikasi berat benih, yaitu I (berat), II (berat sedang), III (sedang), dan IV (ringan). Parameter yang diamati adalah ukuran benih, berat 1000 butir benih, dan daya berkecambah.

4. Pengujian daya berkecambah

Pengujian daya berkecambah dilakukan untuk mengetahui pengaruh metoda ekstraksi dan ukuran benih terhadap daya berkecambah. Metoda pengujiannya menggunakan metoda UDK (Uji Di atas Kertas) di laboratorium.

\section{Analisis Data}

Data hasil penelitian dianalisis dengan menggunakan analisa sidik ragam (Anova). Apabila perlakuan berpengaruh nyata maka dilakukan uji Beda Nyata Terkecil (BNT).

\section{HASIL DAN PEMBAHASAN}

\section{A. Hasil}

\section{Metode ekstraksi benih}

Metode ekstraksi benih dengan pengeringan seed drier menggunakan suhu $45^{\circ} \mathrm{C}$. Sedangkan kondisi cuaca pada saat pengeringan di bawah sinar matahari adalah tidak hujan, dengan lama pengeringan selama 6 jam, mulai pukul $09.00 \mathrm{~s} / \mathrm{d}$ 15.00. Rata-rata suhu dan kelembaban pada pagi hari (pukul 09.00 ) yaitu $32,2^{\circ} \mathrm{C}$ dan $54 \%$; siang hari (pukul 12.00) : $45,7^{\circ} \mathrm{C}$ dan $30 \%$; dan sore hari : $38,8^{\circ} \mathrm{C}$ dan $87 \%$.

Dari hasil sidik ragam pada Tabel 1 menunjukkan bahwa metoda ekstraksi benih dengan pengeringan seed drier dan penjemuran sinar matahari berpengaruh nyata terhadap rendemen benih, kadar air, dan daya berkecambah benih $A$. crassicarpa hasil pemuliaan dan yang belum dimuliakan. 
Tabel(Table) 1. Analisa sidik ragam pengaruh perlakuan ekstraksi benih dengan seed drier dan penjemuran sinar matahari terhadap rendemen benihi, kadar air, dan daya berkecambah benih $A$. crassicarpa hasil pemuliaan dan yang belum dimuliakan (Analysis of variance of the effect seed extraction treatment with seed drier and dried under the sun to seed rendemen, moisture content, and germination percentage of improved and unimproved seed of Acacia crassicarpa)

\begin{tabular}{|c|c|c|c|c|c|c|c|}
\hline \multirow{3}{*}{$\begin{array}{c}\text { Sumber } \\
\text { keragaman } \\
\text { (Source of } \\
\text { variance) }\end{array}$} & \multirow{3}{*}{$\begin{array}{c}\text { Derajat } \\
\text { bebas } \\
\text { (Degree } \\
\text { of } \\
\text { freedom) }\end{array}$} & \multicolumn{6}{|c|}{ Kuadrat Tengah (Mean of square) } \\
\hline & & \multicolumn{3}{|c|}{ Seed drier } & \multicolumn{3}{|c|}{$\begin{array}{c}\text { Penjemuran sinar matahari } \\
(\text { Dried under the sun })\end{array}$} \\
\hline & & $\begin{array}{l}\text { Rendemen } \\
\text { benih } \\
\text { (seed } \\
\text { rendemen) }\end{array}$ & $\begin{array}{l}\text { Kadar air } \\
\text { (Moisture } \\
\text { content) }\end{array}$ & $\begin{array}{c}\text { Daya berkecambah } \\
\text { (Germination } \\
\text { percentage) }\end{array}$ & $\begin{array}{l}\text { Rendemen } \\
\text { benih } \\
\text { (Seed } \\
\text { rendemen) }\end{array}$ & $\begin{array}{l}\text { Kadar air } \\
\text { (Moisture } \\
\text { content) }\end{array}$ & $\begin{array}{l}\text { Daya } \\
\text { berkecambah } \\
\text { (Germination } \\
\text { percentage) }\end{array}$ \\
\hline $\begin{array}{l}\text { Sumber benih } \\
\text { (Seed source) }\end{array}$ & 1 & $4,7888^{*}$ & $7,5377^{*}$ & $578,0017 *$ & $94,6430 *$ & $3,2274 *$ & $1643,6267^{*}$ \\
\hline $\begin{array}{l}\text { Perlakuan } \\
\text { (Treatment) }\end{array}$ & 10 & $29,1814^{*}$ & $27,3536^{*}$ & $73,7559^{*}$ & $13,5044^{*}$ & $54,6923^{*}$ & $72,2100 *$ \\
\hline Sisa (Residual) & 24 & 0,0002 & 0,0341 & 22,8993 & 0,00003 & 0,0415 & 23,4288 \\
\hline Total (Total) & 35 & & & & & & \\
\hline
\end{tabular}

Keterangan(Remarks) ${ }^{*}=$ Berpengaruh nyata pada tingkat kepercayaan 95\% (significant at 95\% confidencelevel)

Tabel(Table) 2. Rata-rata rendemen benih A. crassicarpa hasil pemuliaan dan yang belum dimuliakan berdasarkan perlakuan seed drier dan penjemuran sinar matahari (Uji BNT) (Average of seed rendemen of improved and unimproved seed of A. crassicarpa based on seed drier and dried under the sun (BNT test))

\begin{tabular}{|c|c|c|c|c|c|c|c|c|c|c|}
\hline \multirow{3}{*}{$\begin{array}{l}\text { Kelompok } \\
\text { Sumber Benih } \\
\text { (Seed Source) }\end{array}$} & \multicolumn{10}{|c|}{ Rendemen benih (gram) } \\
\hline & \multicolumn{5}{|c|}{ Seed Drier (Jam/Hours) } & \multicolumn{5}{|c|}{ Penjemuran (Hari) (Dried under the sun (day)) } \\
\hline & 1 & 2 & 3 & 4 & 5 & 1 & 2 & 3 & 4 & 5 \\
\hline $\begin{array}{l}\text { Hasil Pemuliaan } \\
\text { (Improve) }\end{array}$ & $8,79 \mathrm{a}$ & $12,65 \mathrm{a}$ & $16,28 \mathrm{a}$ & $21,16 \mathrm{a}$ & $21,17 \mathrm{a}$ & $17,97 \mathrm{a}$ & $27,24 \mathrm{a}$ & $30,82 \mathrm{a}$ & $30,84 a$ & $30,85 a$ \\
\hline $\begin{array}{l}\text { Belum } \\
\text { Dimuliakan } \\
\text { (Unimprove) }\end{array}$ & $5,95 b$ & $3,84 b$ & $13,79 b$ & $19,18 b$ & $19,19 b$ & $14,38 b$ & $20,81 b$ & $21,22 b$ & $21,24 b$ & $21,26 b$ \\
\hline
\end{tabular}

Tabel(Table) 3. Rata-rata kadar air benih A. crassicarpa hasil pemuliaan dan yang belum dimuliakan berdasarkan perlakuan seed drier dan penjemuran sinar matahari (Uji BNT) (Average of seed moisture content of improved and unimproved seed of A. crassicarpa based on seed drier and dried under the sun (BNT test))

\begin{tabular}{ccccccccccc}
\hline \multirow{2}{*}{$\begin{array}{c}\text { Kelompok } \\
\text { Sumber Benih } \\
\text { (Seed Source) }\end{array}$} & \multicolumn{8}{c}{ Seed drier (Jam/hours) } & \multicolumn{5}{c}{ Penjemuran (Hari) (Dried under the sun (day) } \\
\cline { 2 - 10 } & 1 & 2 & 3 & 4 & 5 & 1 & 2 & 3 & 4 & 5 \\
\hline $\begin{array}{c}\text { Hasil Pemuliaan } \\
\text { (Improve) } \\
\text { Belum } \\
\begin{array}{c}\text { Dimuliakan } \\
\text { (Unimprove) }\end{array}\end{array}$ & $8,79 \mathrm{a}$ & $12,65 \mathrm{a}$ & $16,28 \mathrm{a}$ & $21,16 \mathrm{a}$ & $21,17 \mathrm{a}$ & $17,97 \mathrm{a}$ & $27,24 \mathrm{a}$ & $30,82 \mathrm{a}$ & $30,84 \mathrm{a}$ & $30,85 \mathrm{a}$ \\
\hline Keterangan (Remarks) : Angka-angka yang diikuti oleh huruf yang sama menunjukkan tidak adanya perbedaan nyata pada \\
$\begin{array}{l}\text { tingkat kepercayaan 95\% (Values followed by the same letter are not significantly different at 95\% } \\
\text { confidencelevel) }\end{array}$
\end{tabular}


Tabel(Table) 4. Rata-rata daya berkecambah benih A. crassicarpa hasil pemuliaan dan yang belum dimuliakan berdasarkan perlakuan seed drier dan penjemuran sinar matahari (Uji BNT) (Average of germination percentage of improved and unimproved seed of improved and unimproved seed of A. crassicarpa based on seed drier and dried under the sun (BNTtest))

\begin{tabular}{|c|c|c|c|c|c|c|c|c|c|c|}
\hline \multirow{3}{*}{$\begin{array}{c}\text { Kelompok } \\
\text { Sumber Benih } \\
\text { (Seed Source) }\end{array}$} & \multicolumn{10}{|c|}{ Daya berkecambah (\%) } \\
\hline & \multicolumn{5}{|c|}{ Seed drier (Jam/hours) } & \multicolumn{5}{|c|}{ Penjemuran (Hari) (Dried under the sun (day) } \\
\hline & 1 & 2 & 3 & 4 & 5 & 1 & 2 & 3 & 4 & 5 \\
\hline $\begin{array}{l}\text { Hasil Pemuliaan } \\
\text { (Improve) } \\
\text { Belum }\end{array}$ & $8,79 \mathrm{a}$ & $12,65 \mathrm{a}$ & $16,28 \mathrm{a}$ & $21,16 \mathrm{a}$ & $21,17 \mathrm{a}$ & $17,97 \mathrm{a}$ & $27,24 a$ & $30,82 \mathrm{a}$ & $30,84 a$ & $30,85 a$ \\
\hline $\begin{array}{l}\text { Dimuliakan } \\
\text { (Unimprove) }\end{array}$ & $5,95 b$ & $3,84 \mathrm{~b}$ & $13,79 b$ & $19,18 b$ & $19,19 b$ & $14,38 b$ & $20,81 b$ & $21,22 b$ & $21,24 b$ & $21,26 b$ \\
\hline
\end{tabular}

Keterangan(Remarks): Angka-angka yang diikuti oleh huruf yang sama menunjukkan tidak adanya perbedaan nyata pada tingkat kepercayaan 95\% (Values followed by the same letter are not significantly different at $95 \%$ confidencelevel)

Untuk mengetahui perbedaan terhadap rendemen benih, kadar air, dan daya berkecambah benih $A$. crassicarpa hasil pemuliaan dan yang belum dimuliakan, maka dilakukan uji beda ratarata dengan Uji Beda Nyata Terkecil (BNT) yang disajikan pada Tabel 2, 3, dan 4 .

\section{Ukuran benih}

Ukuran benih dapat ditunjukkan berdasarkan ukuran dimensi benih (panjang, lebar, tebal) dan berdasarkan berat benih (berat 1000 butir benih). Sortasi benih krasikarpa berdasarkan ukuran mesh/ ayakan diperoleh 3 klasifikasi ukuran benih, yaitu ukuran besar (tertahan di ayakan berukuran 2,4 x $2 \mathrm{~mm}$ ), ukuran sedang (lolos dari ayakan berukuran 2,4 × $2 \mathrm{~mm}$ dan tertahan di ayakan berukuran 2 x 1,9 mm), dan ukuran kecil (lolos dari ayakan berukuran $2 \times 1,9 \mathrm{~mm}$ ).

Kisaran rata-rata ukuran benih $A$. crassicarpa hasil pemuliaan dan yang belum dimuliakan berdasarkan perlakuan ayakan/mesh dicantumkan pada Tabel 5 .

Sedangkan kisaran rata-rata berat 1.000 butir benih $A$. crassicarpa berdasarkan klasifiaksi berat (Seed Gravity Table) disajikan pada Tabel 6.

Berdasarkan hasil sidik ragam (Tabel 7) menunjukkan bahwa ukuran dan klasifikasi berat benih berpengaruh nyata terhadap daya berkecambah benih A.crassicarpa hasil pemuliaan dan yang belum dimuliakan.

Untuk mengetahui perbedaan ukuran benih terhadap daya berkecambah benih A.crassicarpa hasil pemuliaan dan yang belum, maka dilakukan uji beda rata-rata dengan Uji Beda Nyata Terkecil (BNT) yang disajikan pada Tabel 8.

Sedangkan untuk mengetahui perbedaan klasifikasi berat benih terhadap daya berkecambah

Tabel(Table) 5. Kisaran rata-rata ukuran benih A. crassicarpa hasil pemuliaan dan yang belum dimuliakan berdasarkan ukuran ayakan (mesh) (Range of average of improved and unimproved seed of A. crassicarpa seed size based on sieve (mesh size))

\begin{tabular}{|c|c|c|c|c|c|c|c|c|c|c|}
\hline \multirow{3}{*}{ No } & \multirow{3}{*}{$\begin{array}{l}\text { Kelompok } \\
\text { Sumber } \\
\text { Benih } \\
\text { (Seed } \\
\text { Source) }\end{array}$} & \multicolumn{9}{|c|}{ Ukuran Benih $(\mathrm{mm})(\mathrm{X} \pm \mathrm{SD})$} \\
\hline & & \multicolumn{3}{|c|}{ Kecil } & \multicolumn{3}{|c|}{ Sedang } & \multicolumn{3}{|c|}{ Besar } \\
\hline & & Panjang & Lebar & Tebal & Panjang & Lebar & Tebal & Panjang & Lebar & Tebal \\
\hline \multirow[t]{2}{*}{1} & Hasil & $5.347 \pm$ & $2.537 \pm$ & $0.022 \pm$ & $5.464 \pm$ & $2.619 \pm$ & $0.022 \pm$ & $5.850 \pm$ & $2.738 \pm$ & $0.030 \pm$ \\
\hline & $\begin{array}{l}\text { Pemuliaan } \\
\text { (Improve) }\end{array}$ & 0.160 & 0.051 & 0.002 & 0.051 & 0.015 & 0.000 & 0.074 & 0.051 & 0.001 \\
\hline 2 & $\begin{array}{l}\text { Belum } \\
\text { Dimuliakan } \\
\text { (Unimprove) }\end{array}$ & $\begin{array}{c}5.225 \pm \\
0.028\end{array}$ & $\begin{array}{c}2.475 \pm \\
0.033\end{array}$ & $\begin{array}{c}0.029 \pm \\
0.021\end{array}$ & $\begin{array}{c}5.271 \pm \\
0.099\end{array}$ & $\begin{array}{c}2.546 \pm \\
0.029\end{array}$ & $\begin{array}{c}0.021 \pm \\
0.001\end{array}$ & $\begin{array}{l}5.381 \pm \\
0.115\end{array}$ & $\begin{array}{l}2.669 \pm \\
0.044\end{array}$ & $\begin{array}{l}0.024 \pm \\
0.001\end{array}$ \\
\hline
\end{tabular}

Keterangan(Remarks): Angka-angka yang diikuti oleh huruf yang sama menunjukkan tidak adanya perbedaan nyata pada tingkat kepercayaan 95\% (Values followed by the same letter are not significantly different at $95 \%$ confidencelevel) 
Tabel(Table) 6. Kisaran rata-rata berat 1.000 butit benih $A$. crassicarpa hasil pemuliaan dan yang belum dimuliakan berdasarkan/seed gravity table (range of average of improved and unimproved seed of A. crassicarpa seed size based on gravity table)

\begin{tabular}{|c|c|c|c|c|c|}
\hline \multirow[b]{2}{*}{ No. } & \multirow{2}{*}{$\begin{array}{l}\text { Kelompok sumber } \\
\text { Benih (Seed source) }\end{array}$} & \multicolumn{4}{|c|}{ Berat 1.000 butir benih $(\mathrm{gr})(\mathrm{X} \pm \mathrm{SD})$} \\
\hline & & $\begin{array}{c}\mathrm{I} \\
\text { (Berat) }\end{array}$ & $\begin{array}{c}\text { II } \\
\text { (Berat sedang) }\end{array}$ & $\begin{array}{c}\text { III } \\
\text { (Sedang) }\end{array}$ & $\begin{array}{c}\text { IV } \\
\text { (Ringan) }\end{array}$ \\
\hline 1 & $\begin{array}{l}\text { Hasil Pemuliaan } \\
\text { (Improve) }\end{array}$ & $22,08 \pm 0,58$ & $21,30 \pm 0,74$ & $20,61 \pm 0,27$ & $18,53 \pm 1,50$ \\
\hline 2 & $\begin{array}{l}\text { Belum Dimuliakan } \\
\text { (Unimprove) }\end{array}$ & $21,77 \pm 0,39$ & $20,20 \pm 0,84$ & $19,63 \pm 0,28$ & $18,48 \pm 0,28$ \\
\hline
\end{tabular}

Keterangan(Remarks): Angka-angka yang diikuti oleh huruf yang sama menunjukkan tidak adanya perbedaan nyata pada tingkat kepercayaan $95 \%$ (Values followed by the same letter are not significantly different at $95 \%$ confidencelevel)

Tabel(Table) 7. Analisa sidik ragam pengaruh ukuran dan klasifikasi berat benih terhadap daya berkecambah benih $A$. crassicarpa hasil pemuliaan dan yang belum dimuliakan (Analysis of variance of the effect size and classification of seed size to germination percentage of improved and unimproved seed of A. crassicarpa)

\begin{tabular}{lcccc}
\hline \multirow{2}{*}{$\begin{array}{l}\text { Sumber keragaman } \\
\text { (Source of variance) }\end{array}$} & \multicolumn{2}{c}{$\begin{array}{c}\text { Ukuran benih } \\
\text { (Seed size) }\end{array}$} & $\begin{array}{c}\text { Klasifikasi berat benih } \\
\text { (Classification of seed size) }\end{array}$ \\
\cline { 2 - 5 } & $\begin{array}{c}\text { Derajat Bebas } \\
\text { (Degree of freedom) }\end{array}$ & $\begin{array}{c}\text { Kuadrat tengah } \\
\text { (Mean of square) }\end{array}$ & $\begin{array}{c}\text { Derajat bebas } \\
\text { (degree of freedom) }\end{array}$ & $\begin{array}{c}\text { Kuadrat tengah } \\
\text { (Mean of square) }\end{array}$ \\
\hline $\begin{array}{l}\text { Sumber Benih } \\
\text { (seed source) }\end{array}$ & 1 & $833,68 *$ & 1 & $425,04 *$ \\
$\begin{array}{l}\text { Perlakuan } \\
\text { (treatment) }\end{array}$ & 4 & $106,91 *$ & 6 & $78,39 *$ \\
Sisa (residual) & 12 & 7,56 & 16 & 11,58 \\
\hline Total (total) & 17 & & 23 & \\
\hline
\end{tabular}

Keterangan (Remarks) : * Berpengaruh nyata pada tingkat kepercayaan 95\% (Significant at 95\% confidencelevel)

Tabel (Table) 8. Rata-rata daya berkecambah benih berdasarkan ukuran benih A.crassicarpa hasil pemuliaan dan yang belum dimuliakan dari perlakuan ayakan/mesh (Uji BNT) (Average of germination percentage based on of improved and unimproved seed of A.crassicarpa seed size with sieve/mesh size treatment (BNTtest))

\begin{tabular}{|c|c|c|c|c|}
\hline \multirow[b]{2}{*}{ No } & \multirow{2}{*}{$\begin{array}{l}\text { Kelompok sumber benih } \\
\text { (Seed source) }\end{array}$} & \multicolumn{3}{|c|}{ Daya berkecambah (Germination percentage) (\%) } \\
\hline & & $\begin{array}{c}\text { Ukuran kecil } \\
\text { (Small size) }\end{array}$ & $\begin{array}{l}\text { Ukuran sedang } \\
\text { (Medium size) }\end{array}$ & $\begin{array}{l}\text { Ukuran besar } \\
\text { (Large size) }\end{array}$ \\
\hline 1 & Hasil Pemuliaan (Improve) & $86 \mathrm{a}$ & $90 \mathrm{a}$ & $93 \mathrm{a}$ \\
\hline 2 & Belum Dimuliakan (Unimprove) & $68 \mathrm{~b}$ & $78 \mathrm{~b}$ & $82 \mathrm{~b}$ \\
\hline
\end{tabular}

Keterangan(Remarks): Angka-angka yang diikuti oleh huruf yang sama menunjukkan tidak adanya perbedaan nyata pada tingkat kepercayaan $95 \%$

Tabel(Table) 9. Rata-rata daya berkecambah benih A.crassicarpa hasil pemuliaan dan yang belum berdasarkan klasifikasi berat benih (seed grafity table) (Uji BNT) (Average of germination percentage of improved and unimproved seed A.crassicarpa based on classification of seed size with seed grafity table (BNT test))

\begin{tabular}{lcccc}
\hline \multirow{2}{*}{$\begin{array}{c}\text { Kelompok Sumber } \\
\text { Benih }\end{array}$} & \multicolumn{4}{c}{ Daya Berkecambah (\%) } \\
\cline { 2 - 5 } & Berat (weight) & $\begin{array}{c}\text { II } \\
\text { Berat Sedang } \\
\text { (weight medium) }\end{array}$ & $\begin{array}{c}\text { Sedang } \\
\text { (medium) }\end{array}$ & $\begin{array}{c}\text { IV } \\
\text { Ringan } \\
\text { (lighty) }\end{array}$ \\
\hline Hasil Pemuliaan & $94 \mathrm{a}$ & $87 \mathrm{a}$ & $88 \mathrm{a}$ & $79 \mathrm{a}$ \\
Belum Dimuliakan & $83 \mathrm{~b}$ & $81 \mathrm{~b}$ & $77 \mathrm{~b}$ & $72 \mathrm{~b}$ \\
\hline
\end{tabular}

Keterangan(Remarks): Angka-angka yang diikuti oleh huruf yang sama menunjukkan tidak adanya perbedaan nyata pada tingkat kepercayaan 95\% (Values followed by the same letter are not significantly different at $95 \%$ confidencelevel) 
benih A.crassicarpa hasil pemuliaan dan yang belum, maka dilakukan uji beda rata-rata dengan Uji BNT yang disajikan pada Tabel 9.

\section{B. Pembahasan}

\section{Metoda ekstraksi benih}

Dilihat dari rendemen/produksi benih yang dihasilkan dari sumber benih hasil pemuliaan dan yang belum dimuliakan, pada perlakuan seed drier diketahui bahwa pengeringan selama 1 sampai dengan 3 jam belum menghasilkan rendemen benih secara optimal pada benih $A$. crassicarpa. Rendemen benih yang banyak diperoleh pada perlakuan seed drier pada pengeringan selama 4 jam. Sedangkan pada perlakuan penjemuran di bawah sinar matahari produksi benih terbanyak diperoleh pada hasil penjemuran selama 3 hari. Hal ini berarti bahwa perlakuan terbaik yang dapat mengoptimalkan rendemen benih tertinggi pada seed drier yaitu pengeringan selama 4 jam. Sedangkan perlakuan terbaik pada penjemuran sinar matahari adalah penjemuran selama 3 hari.

Rendemen/produksi benih yang dihasilkan pada perlakuan seed drier dan penjemuran untuk lokasi sumber benih hasil pemuliaan dapat menghasilkan rendemen benih lebih banyak dibandingkan dengan sumber benih yang belum dimuliakan. Hal ini dapat disebabkan karena rendemen/produksi benih dipengaruhi dari faktor genetik dari sumber benih dan lingkungan. Sumber benih hasil pemuliaan yang telah dikelola dengan baik dapat mempertahankan kualitas genetik yang unggul, sehingga dapat menghasilkan rendemen/ potensi produksi benih yang tinggi (Schmidt, 2000). Selain itu benih yang berasal dari sumber benih hasil pemuliaan memiliki keragaman tinggi sehingga peluang inbreeding sangat kecil. Sehingga proses perkembangan buah menjadi benih dapat sempurna dan hal ini dapat menyebabkan produksi benih dari hasil pemuliaan lebih tinggi dibandingkan dengan yang belum dimuliakan.

Berdasarkan nilai kadar air yang dihasilkan dari sumber benih hasil pemuliaan dan yang belum dimuliakan, terlihat bahwa pada perlakuan pengeringan seed drier selama 1-3 jam, kadar air yang dihasilkan masih tinggi. Sedangkan pada perlakuan pengeringan seed drier selama 4-5 jam, menghasilkan nilai kadar air yang rendah. Pada perlakuan penjemuran matahari, diketahui bahwa pengeringan selama 3-5 hari dapat menghasilkan nilai kadar air yang rendah. Hal ini berarti pada pengeringan seed drier selama 4 jam dan penjemuran sinar matahari selama 3 jam, kan-dungan air di dalam benih sudah bisa diuapkan secara optimal.

Kadar air benih pada perlakuan seed drier dan penjemuran dari sumber benih hasil pemuliaan dapat menghasilkan nilai lebih rendah dibandingkan dengan sumber benih yang belum dimuliakan. Semakin lama dikeringkan di seed drier dan dijemur di bawah sinar matahari akan menyebabkan nilai kadar air benih cenderung semakin menurun pada masing-masing kelompok sumber benih. Untuk perlakuan pengeringan seed drier, nilai kadar air terendah diperoleh pada pengeringan selama 4 jam. Sedangkan pada penjemuran sinar matahari selama 3 hari dapat menghasilkan nilai kadar air benih yang paling kecil.

Benih krasikarpa termasuk benih ortodok. Salah satu faktor yang mempengaruhi periode hidup benih adalah kadar air benih, karena kadar air benih merupakan faktor yang paling penting dalam kemunduran benih. Oleh karena itu diperlukan kadar air benih tertentu untuk mempertahankan viabilitasnya, contohnya untuk benih krasikarpa diperlukan kadar air awal yang rendah yaitu sebesar 4-8\%. Hal ini bisa diperoleh pada perlakuan pengeringan seed drier selama 4 jam atau dengan penjemuran sinar matahari selama 3 hari.

Dari nilai daya berkecambah yang dihasilkan dari sumber benih hasil pemuliaan dan yang belum dimuliakan, menunjukkan bahwa untuk perlakuan seed drier, nilai daya berkecambah tertinggi diperoleh pada pengeringan seed drier selama 4 jam dan pada perlakuan penjemuran, daya berkecambah tertinggi dihasilkan pada penjemuran selama 3 hari. Nilai daya berkecambah tertinggi diperoleh pada perlakuan seed drier 4 jam dan pada perlakuan penjemuran 3 hari yang menghasilkan nilai kadar air benih terendah. Hal ini berarti bahwa pada pengeringan seed drier 4 jam dan penjemuran sinar matahari selama 3 hari merupakan metoda ekstraksi yang sudah optimal untuk mengeluarkan benih dari buah/polong, sehingga dapat menghasilkan rendemen benih yang paling banyak dengan viabilitas benih yang tertinggi.

Daya berkecambah pada perlakuan seed drier dan penjemuran dari sumber benih hasil pemuliaan dapat menghasilkan nilai lebih tinggi dibandingkan dengan sumber benih yang belum dimuliakan. Semakin lama dikeringkan atau dijemur, dapat menghasilkan nilai daya berkecambah cenderung semakin meningkat. Nilai daya berke- 
cambah sangat erat kaitannya dengan nilai kadar air yang dihasilkan. Semakin rendah nilai kadar air, akan menyebabkan nilai daya berkecambah semakin meningkat.

Kadar air merupakan salah satu faktor penting yang mempengaruhi kemampuan benih untuk mempertahankan viabilitasnya (Agrawal, 1980). Dalam batas tertentu, makin rendah kadar air benih makin lama benih tersebut dapat mempertahankan viabilitasnya. Hal ini berlaku untuk benih-benih tipe ortodoks, termasuk benih jenis krasikarpa.

Rendahnya viabilitas benih (daya berkecambah) dapat disebabkan karena kadar airnya masih tinggi, karena pada kadar air yang tinggi dapat terjadi serangan cendawan. Disamping itu, hal ini dapat menyebabkan aktifitas fisiologis benih meningkat, sehingga dapat mempercepat kemunduran mutu benih (Sutopo, 1985). Daya berkecambah pada perlakuan seed drier dan penjemuran dari sumber benih hasil pemuliaan dapat menghasilkan nilai lebih tinggi dibandingkan dengan sumber benih yang belum dimuliakan. Benih yang berasal dari sumber benih hasil pemuliaan memiliki mutu benih lebih tinggi karena benih hasil pemuliaan memiliki keragaman tinggi sehingga peluang inbreeding sangat kecil. Proses inbreeding sering kali menghasilkan benih yang tidak berkembang sempurna sehingga viabilitasnya rendah.

\section{Ukuran benih}

Pada sumber benih hasil pemuliaan memiliki ukuran dan berat benih yang lebih besar dibandingkan dengan sumber benih yang belum dimuliakan. Berat atau ukuran benih dapat digunakan untuk mendeteksi keragaman genetik, karena berat benih sangat dipengaruhi oleh faktor maternal dan berada di bawah kontrol genetik (Scmidt, 2000). Ukuran benih merupakan sifat yang sangat tinggi dapat diwariskan, sehingga dimungkinkan untuk dapat melakukan identifikasi asal benih berdasarkan kualitas benihnya terutama berat dan ukuran benih. Keragaman atau variasi berat benih yang disebabkan oleh kondisi tempat tumbuh dan asal benih telah terbukti pada jenis $\mathrm{Aca}$ cia mangium (Iriantono et al., 2000).

Adanya perbedaan variasi berat dan ukuran benih dari masing-masing klasifikasi sumber benih tersebut dipengaruhi oleh faktor keturunan (genetik) dari pohon induk atau sumber benih dan lingkungan. Benih yang berasal dari pohon induk atau sumber benih yang berbeda mungkin akan mempunyai keragaman berat dan ukuran yang berbeda dan mempunyai respon yang berbeda pula terhadap daya berkecambah dan vigor benihnya sehingga antara lot-lot benih dalam satu jenis yang berbeda pohon induk atau provenannya ada kemungkinan berkorelasi dan tidak berkorelasi dengan daya berkecambah dan vigor benih (Sudrajat, 2006). Selain itu juga kondisi lingkungan tempat tumbuh (letak geografi, iklim, tanah, ketinggian) dimana pohon induk tersebut tumbuh juga berpengaruh (Schmidt, 2000).

Dari hasil penelitian menunjukkan bahwa benih $A$. crassicarpa yang berukuran besar dan paling berat memiliki nilai daya berkecambah lebih tinggi dibandingkan dengan benih berukuran sedang, kecil dan ringan. Semakin besar ukuran dan berat benih akan menghasilkan nilai daya berkecambah cenderung meningkat. Menurut Schmidt (2000), ukuran benih terkadang berkorelasi dengan viabilitas dan vigor benih, dimana benih yang berat cenderung mempunyai vigor yang lebih baik. Benih yang ukurannya besar lebih tinggi daya berkecambahnya karena benih berukuran besar mempunyai embrio dan cadangan makanan yang lebih besar (Hendromono, 1996).

Hasil penelitian ini sejalan dengan penelitian terdahulu bahwa ukuran benih berpengaruh terhadap mutu fisiologis benih, dan semakin besar ukuran benih maka semakin meningkat nilai daya berkecambahnya untuk benih Shorea pinanga (Komar, 1998), benih Hymenaea courbaril (Hendromono 1996), benih Anisoptera costata (Pradjadinata et al. 1991), benih Acacia mangium dan Schleichera oleosa (Suita $d k k ., 2007)$.

\section{KESIMPULAN}

\section{A. Kesimpulan}

1. Metode ekstraksi dan ukuran benih berpengaruh nyata terhadap mutu fisik-fisiologis benih Acacia crassicarpa hasil pemuliaan dan yang belum dimuliakan. Benih $A$. crassicar$p a$ hasil pemuliaan memiliki mutu fisik-fisiologis yang lebih baik dibandingkan dengan yang belum dimuliakan.

2. Metode ekstraksi benih yang terbaik untuk benih $A$. crassicarpa hasil pemuliaan dan yang belum dimuliakan yaitu dengan cara pengeringan seed drier selama 4 jam atau dengan cara penjemuran sinar matahari selama 3 hari.

3. Metode ekstraksi benih $A$. crassicarpa yang dihasilkan dengan perlakuan seed drier dan 
penjemuran untuk lokasi sumber benih hasil pemuliaan dapat menghasilkan rendemen benih lebih banyak, nilai kadar air lebih rendah dan nilai daya berkecambah lebih tinggi dibandingkan dengan sumber benih yang belum dimuliakan.

4. Benih hasil pemuliaan memiliki ukuran dan berat benih yang lebih besar dibandingkan dengan yang belum dimuliakan. Benih yang berukuran besar memiliki viabilitas lebih baik dibandingkan dengan benih berukuran sedang, kecil dan ringan.

\section{B. Saran}

Benih A. crassicarpa hasil pemuliaan merupakan investasi yang penting dan mahal sehingga perlu ditangani dengan benar agar mutu benihnya, baik mutu fisik, fisiologis, dan getetik tetap terjamin baik.

\section{DAFTAR PUSTAKA}

Agrawal, R.L. 1980. Seed Technology. Oxford and IBH Publishing Co. New Delhi.

Barner, H. and Ditlevsen. 1988. Strategies and Procedures for an Integrated National Tree-seed Programe for Seed Procurement, Tree Improvement and Genetic Resources. Lecture Note A1. Danida Forest Seed Centre. Denmark.

Gomez, K.A. dan A.G. Arturo. 1995. Prosedur Statistik untuk Penelitian Pertanian. Edisi Kedua. Penerbit Universitas Indonesia. Jakarta.

Hamzah, Z. 1984. Diktat Ilmu Tanah Hutan. Institut Pertanian Bogor.

Hendromono. 1996. Pengaruh Ukuran Benih Terhadap Persen Jadi dan Pertumbuhan Bibit Hymenaea courbaril L. Buletin Teknologi Perbenihan. 3(2): 48 - 53. Bogor.

IFSP. 2000. Pengaruh dari kegiatan penanganan benih dan persemaian terhadap mutu benih. Bahan kursus biologi benih 7 - 18 Februari di Bogor.
Irianto, D., S. Suriarahardja, R.H. Suhendro dan B. Herysetiono. 1999. Percobaan Introduksi $\mathrm{Aca}$ cia spp. Asal Australia dan PNG di Parung Panjang, Bogor, Jawa Barat. LUC No. 281. Balai Teknologi Perbenihan. Badan Penelitian dan Pengembangan Kehutanan. Bogor.

Komar, T.E. 1988. Pemilihan Benih Shorea pinanga Scheff. Berdasarkan Ukuran Benih. LUC No. 40. Departemen Kehutanan. Dirjen Reboisasi dan Rehabilitasi Lahan. Bogor.

Leksono, B. 2009. Pemuliaan Tanaman Hutan. Rencana Penelitian Integratif. Badan Penelitian dan Pengembangan Kehutanan. Bogor.

Sapulete, E. 1996. Perlakuan awal untuk mempercepat perkecambahan benih Acacia crassicarpa. Buletin Penelitian Kehutanan. Vol.11. BPK Pematang Siantar.

Schmidt, L. 2000. Pedoman Penanganan Benih Tanaman Hutan Tropis dan Sub Tropis. Direktorat Jenderal Rehabilitasi Lahan dan Perhutanan Sosial Indonesia Forest Seed Project. PT. Gramedia. Jakarta.

Sudrajat, D.J. dan D. Haryadi. 2006. Berat dan Ukuran Sebagai Tolok Ukur dalam Proses Sortasi dan Seleksi Benih Tanaman Hutan. Info Benih Vol. II (1). Pusat Penelitian dan Pengembangan Hutan Tanaman. Badan Penelitian dan Pengembangan Kehutanan. Departemen Kehutanan.

Suita, E., Nurhasybi dan E. Ismiati. 2007. Pengaruh Berat dan Ukuran Benih Terhadap Perkecambahan dan Pertumbuhan Bibit Mangium ( $\mathrm{Aca}$ cia mangium) dan Kesambi (Schleichera oleosa). Laporan Hasil Penelitian. Balai Penelitian Teknologi Perbenihan Bogor (Tidak Diterbitkan).

Sutopo, L. 1985. Teknologi Benih. CV. Rajawali. Jakarta.

Willan, R.L. 1985. A Guide to Forest Seed Handling. FAO. Forestry Paper 20/2. Rome.

Pradjadinata, S., N. Mindawati, dan T. Rostiwati. 1991. Some Notes on the Characteristics of Dipterocapaceae Seeds. Fourth Round-Table Conference on Dipterocaps. Biotrop Special Publication No. 41. Bogor. Indonesia. 